\title{
Species and composition of phytoplankton in Fushan Bay
} Dongfang Yang ${ }^{1,2}$ a, Zijun $\mathrm{Xu}^{1}$, Qi Zhang ${ }^{1}$, Yiting $\mathrm{Liu}^{1}$, Zhaodang Ma ${ }^{1}$

${ }^{1}$ North China Sea Environmental Monitoring Center, SOA, Qingdao 266033, China;

${ }^{2}$ College of Life, Shanghai Ocean University, Shanghai, 201306, China.

adfyang_dfyang@126.com

Keywords: Phytoplankton, Genus, Specie, Composition, Water temperature, Fushan Bay.

\begin{abstract}
This paper analyzed the species and composition of phytoplankton in Fushan Bay based on investigation data on June to August 2002. Results showed that there were 4 phyla, 39 genera and 102 species, including Bacillariophyta, Pyrrophyta, Chlorophyta and Chrysophyta. There were 29 genera and 75 species for Bacillariophyta, 8 genera and 55 species for Pyrrophyta, 1 genera and 1 species for Chlorophyta, and 1 genera and 1 species for Chrysophyta, respectively. Phytoplankton in this bay was dominated by Bacillariophyta and Pyrrophyta, whose genera and species were increasing from north to south, along with the increasing of water temperature.
\end{abstract}

\section{Introduction}

Phytoplankton is playing double-acting role in marine ecosystem [1]. On one hand, phytoplankton is the basis of marine food chain, which is the core of marine ecosystem. On the other hand, atmosphere $\mathrm{CO}_{2}$ is mainly absorbed and removed by phytoplankton by means of photosynthesis. Therefore, understanding the specific composition of phytoplankton in marine environment is of great significance. The major purpose of this paper was to analyze the species and composition of phytoplankton in Fushan Bay based on investigation data on June to August 2002, and to provide basis for ecological environmental protection.

\section{Material and method}

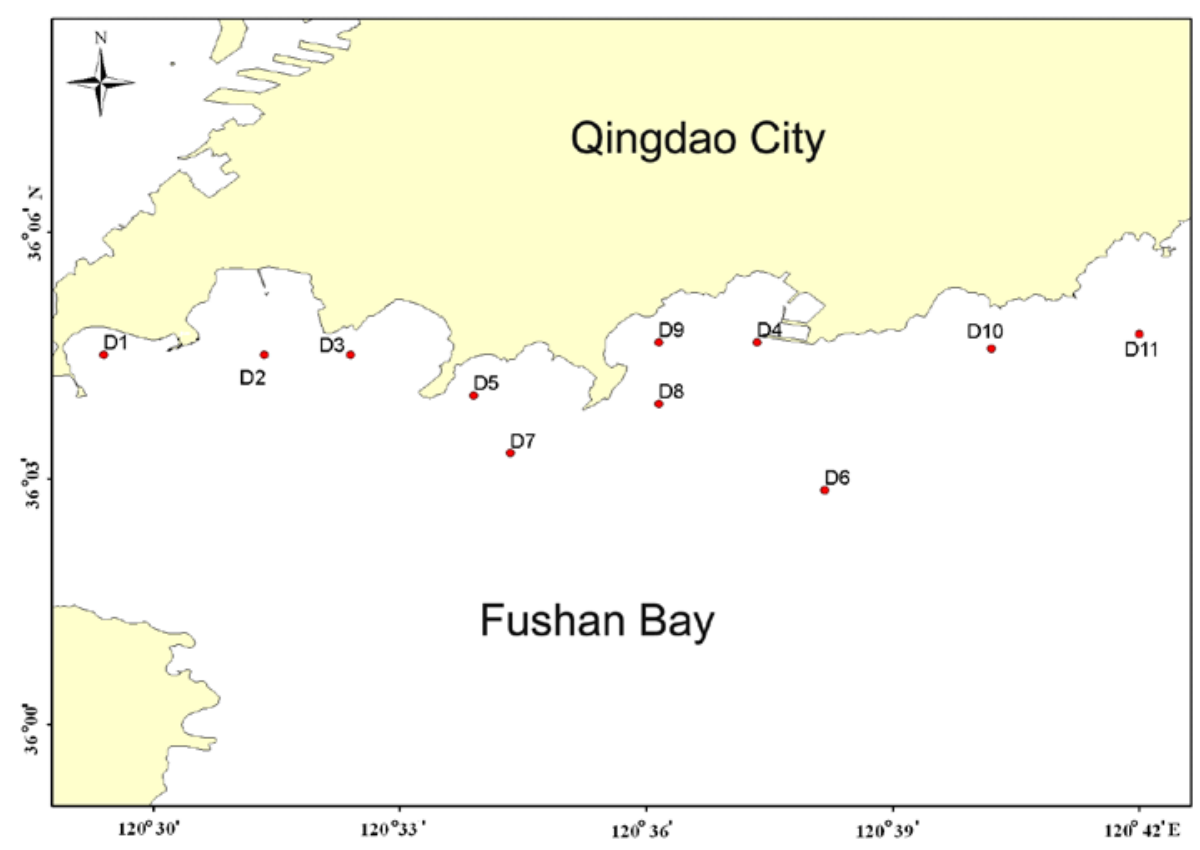

Fig.1 Sampling sites in Fushan Bay 
Loushan Bay $\left(36^{\circ} 00^{\prime}-36^{\circ} 06^{\prime} \mathrm{N}, 120^{\circ} 29^{\prime}-120^{\circ} 42^{\prime} \mathrm{E}\right)$ is located in the south of Qingdao, Shandong Province, eastern China (Fig. 1). The water depth of Fushan Bay ranges form 9-30 m, and the coastline is about $7 \mathrm{~km}$. This bay was the major division of sailing in 2008 Beijing 2008 Olympics Games.

The data was provided by North China Sea Environmental Monitoring Center. Eleven monitoring sites were set up, and the survey was conducted in June to August 2002. The sampling method was followed by National Specification for Marine Monitoring [2], and the species identification was follow by Hu et al. [3].

\section{Results and discussion}

Species and composition of Phytoplankton. During June to August 2002, there were 4 phyla, 39 genera and 102 species, including Bacillariophyta, Pyrrophyta, Chlorophyta and Chrysophyta in Fushan Bay (Table 1). There were 29 genera and 75 species for Bacillariophyta, 8 genera and 55 species for Pyrrophyta, 1 genera and 1 species for Chlorophyta, and 1 genera and 1 species for Chrysophyta, respectively. Obviously, phytoplankton in this bay was dominated by Bacillariophyta and Pyrrophyta.

Species and composition of Bacillariophyta and Pyrrophyta. There were 29 genera and 75 species for Bacillariophyta, in which there were 14, 11, 8, 5, and 4 species for Chaetoceros, Coscinodiscus, Rhizosolenia, Nitzschia and Pleurosigma, respectively; 2 species for Thalassiosira, Thalassionema, Pleurosigma, Hemiaulus, Eucampia, Scenedesmus, Pleurosigma and Bacteriastrum; and 1 specie for the other genera. There were 8 genera and 25 species for Pyrrophyta, in which there were 11, 7 and 2 species for Peridinium, Ceratium and Noctiluca, respectively; and 1 specie for the other genera.

Spatial distribution of phytoplankton. The species and composition of surrounding waters were compared with Fushan Bay in order to reveal the spatial distribution of phytoplankton. The results of the investigation on phytoplankton in waters near by Guangzhou in May 2003 to May 2004 showed that there were 89 genera and 209 species, in which there were 41 genera and 122 species for Bacillariophyta [4]. The results of the investigation on phytoplankton in waters near by Hongkong in 2004 showed that there were 196 species, in which there were 48 genera and 139 species for Bacillariophyta, and 18 genera and 48 species for Pyrrophyta [5]. The dimensionality of Fushan, Guangzhou and Hongkong sea area s were from decreasing from north to south, hence the water temperature in where were increasing from north to south. It was clearly that both genera and species of Bacillariophyta and Pyrrophyta were increasing from north to south, along with the increasing of water temperature.

Table 1 Phytoplankton species in Fushan Bay in June to September 2002.

\begin{tabular}{|c|c|}
\hline Genus & Specie \\
& Chaetoceros castracanei karsten \\
& Chaetoceros densus (Cleve) Cleve \\
Chaetoceros didymus Ehrenberg \\
Chaetoceros curvisetus Cleve \\
Chaetoceros subsecundus (Grunow)Hustedt \\
Chaetoceros affinis Lauder \\
Chaetoceros nipponica Ikari \\
Chaetoceros spp. \\
Chactoceros pseudocurvisetus Margin \\
Chaetoceros compressus Lauder \\
Chaetoceros lorenzianus Grunow \\
Chaetoceros eibenii Grunow
\end{tabular}




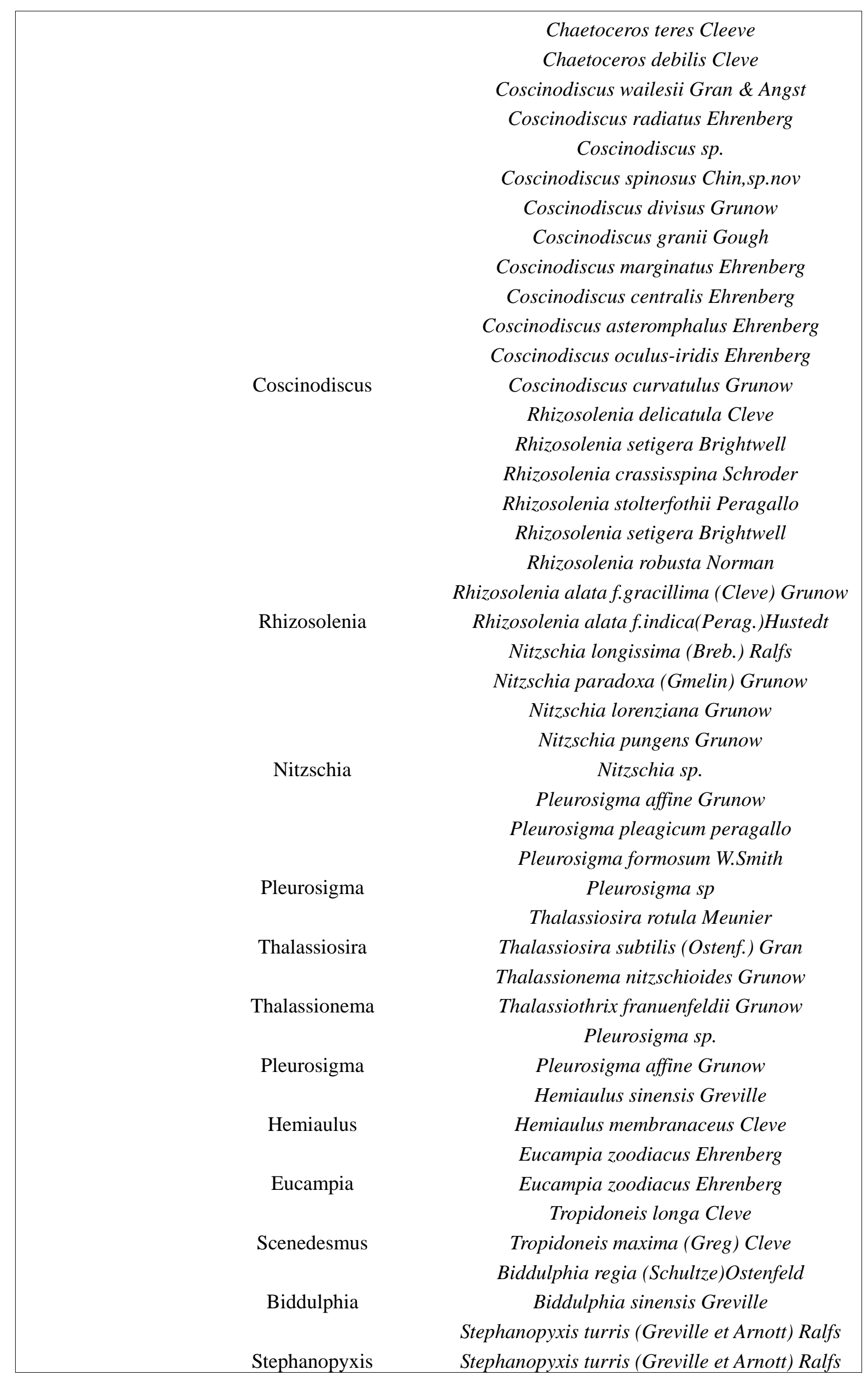




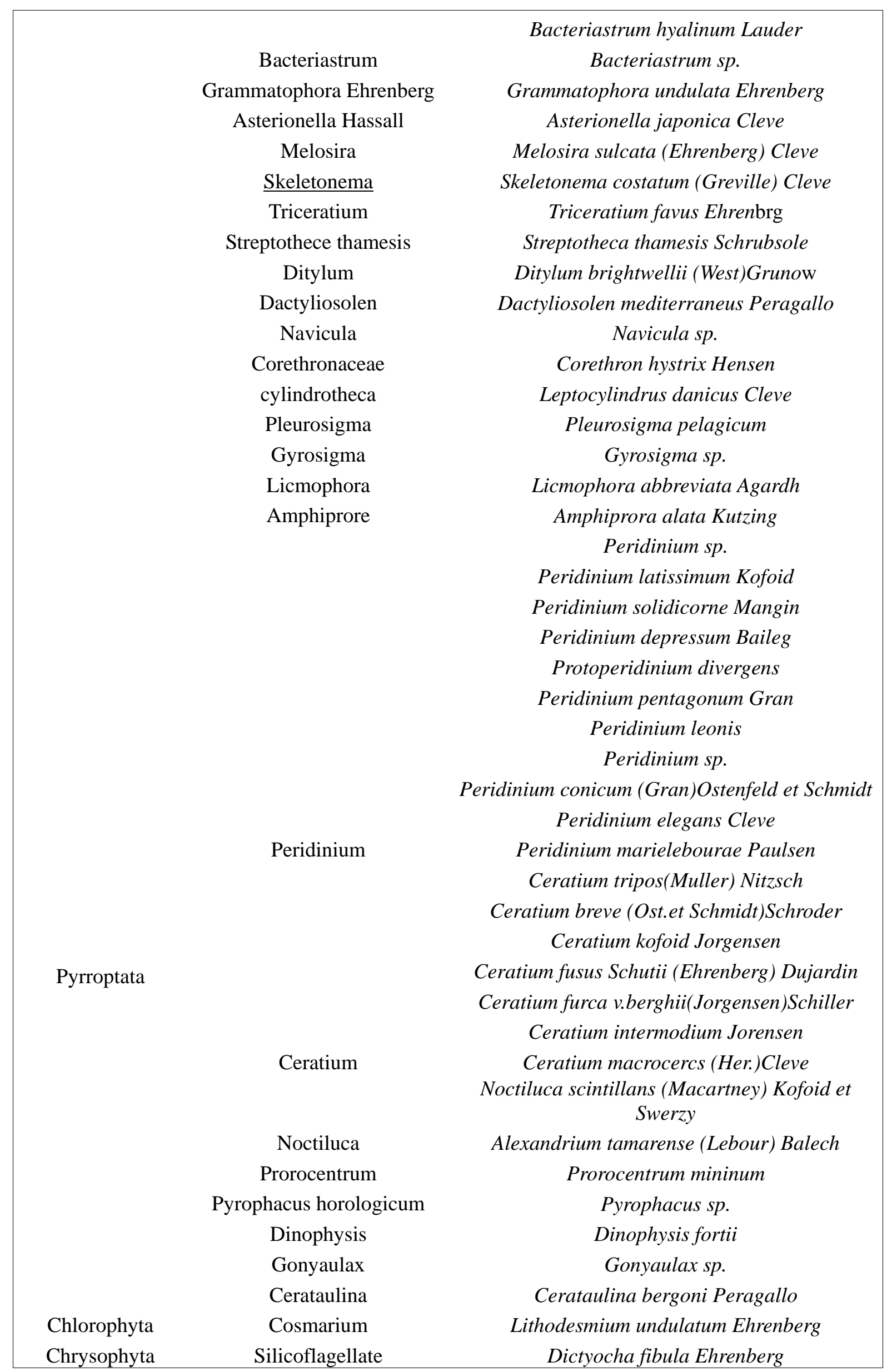




\section{Conclusion}

There were 4 phyla, 39 genera and 102 species phytoplankton in Fushan Bay, including Bacillariophyta, Pyrrophyta, Chlorophyta and Chrysophyta. There were 29 genera and 75 species for Bacillariophyta, 8 genera and 55 species for Pyrrophyta, 1 genera and 1 species for Chlorophyta, and 1 genera and 1 species for Chrysophyta, respectively. Phytoplankton in this bay was dominated by Bacillariophyta and Pyrrophyta, whose genera and species were increasing from north to south, along with the increasing of water temperature.

\section{Acknowledgement}

This paper was sponsored by Ocean Public Welfare Scientific Research Project, State Oceanic Administration of China (No. 201005014) and Scientific Research Funds of the State Oceanic Administration of the North Sea Monitoring Center (No. 05EMC16).

\section{References}

[1] Dongfang Yang, Jianping Wu, Yanfeng Qu et al.: Advance in Marine Science, Vol, 25 (2007), p. 117-122. (in Chinese)

[2] China's State Oceanic Administration: The specification for marine monitoring (Ocean Press, Beijiang 1991). (in Chinese)

[3] Hongjun $\mathrm{Hu}$, Yaoying Li, Yinxin Wei et al.: Chinese freshwater algae (Shanghai Environmental Science Pres, Shanghai 1980). (in Chinese)

[4] Jieping Feng, Sheng Jiang, Jiahe Feng et al.: Ecological Science, Vol. 25(2006), p. 210-212. (in Chinese)

[5] Xuyin Lin, xiaoli Xing, Jianzong He et al.: Marine Science Bulletin, Vol. 27 (2008), p. 23-29. (in Chinese) 